Purpose. Highlighting the peculiarities of a healthy lifestyle culture formation with future cyber security specialists.

Methods. During the research, theoretical and empirical methods are used.

Results. The research of a healthy lifestyle culture formation peculiarities with future cyber security specialists showed the low level and also the further improvement of theoretical and practical aspects of the students healthy lifestyle culture formation.

Originality. The main directions, principles and ways of a healthy lifestyle culture formation among students are determined. The results of the cyber security students questionnaire for the purpose of healthy lifestyle are proposed and analyzed. The conclusion is made about the urgency of the issue of work organization on the formation of a healthy lifestyle culture within a higher education institution, especially for cyber security specialists.

Conclusion. Rapid scientific and technological progress, internal socio-economic transformations of society put higher demands on high school students, especially with regard to the highly relevant "Cyber Security» specialty. This, in its turn, requires a substantial increase in the physical and spiritual potential among the students of this specialty. Consequently, it is necessary to involve student youth in a healthy lifestyle through all available types and forms of activity in higher education institutions. This will help preserve and change the health of the younger generation and lay the foundations for a healthy lifestyle in the next generations.

Key words: health, healthy lifestyle, cyber security specialists.

Одержано редакиією 18.10 .2018 . Прийнято до публікаиї̈ 21.10.2018 p.

УДК 371.321.4 : 514

DOI 10.31651/2524-2660-2018-16-57-73

ТАРАСЕНКОВА Ніна Анатоліївна, доктор педагогічних наук, професор, завідувач кафедри математики та методики навчання математики, Черкаський національний університет імені Богдана Хмельницького e-mail: ntaras7@ukr.net https://orcid.org/0000-0002-6418-6380

\title{
СЕРДЮК Зоя Олексіївна,
}

кандидат педагогічних наук, доцент, доцент кафедри математики та методики навчання математики, Черкаський національний університет імені Богдана Хмельницького e-mail: serdyuk_z@ukr.net https://orcid.org/0000-0002-9376-4346

\section{ОРГАНІЗАЦІЯ ВИВЧЕННЯ ОБ'СМІВ ГЕОМЕТРИЧНИХ ТІЛ У СТАРШІЙ ПРОФІЛЬНІЙ ШКОЛІ НА РІВНІ СТАНДАРТУ}

Розглянуто особливості організаиї̈ вивчення об'ємів геометричних тіл на рівні стандарту в курсі геометрії 11 класу (об'єми многогранників, об'єми ициліндра і конуса, об 'єм кулі). 3'ясовано, що вдалий добір практичних й прикладних задач та дидактично виважена організація їх розв'язування сприяють більш ефективному засвоєнню учнями старшої профільної школи матеріалу зі стереометрії.

Ключові слова: вивчення стереометрії, об'єми геометричних тіл, рівень стандарту. 
Постановка проблеми. Освіта на сучасному етапі розвитку характеризується посиленою увагою до учня, його всебічного розвитку, уміння знайти своє місце в суспільстві, мати змогу максимально самореалізуватися в суспільстві, а тому школа однією з основних своїх цілей ставить досягнення розвитку тих здібностей особистості, які потрібні і людині, й суспільству $[11 ; 12 ; 14]$. Найважливіший внесок математичної освіти в загальний розвиток учнів полягає в інтенсивному формуванні в них спроможності доказово i несуперечливо міркувати, аналізувати, порівнювати, узагальнювати тощо, загалом, уміння робити правильні висновки та будувати реалістичні прогнози. Усі ці навички учні якраз і можуть сформувати й розвинути під час вивчення геометрії. Проте саме засвоєння курсу стереометрії викликає в школярів чимало утруднень $[4 ; 5 ; 10]$.

Аналіз актуальних досліджень. Проблемам навчання систематичного курсу стереометрії присвячено чимало досліджень (М. Бурда, Г. Бевз, В. Бевз, С. Іванова, Н. Гібалова, А. Прус, І. Сверчевська, О. Семенович, І. Тесленко, Р. Черкасов, І. Шаригін та ін.). Особливості організації навчальної діяльності учнів на уроках математики розглядалися в роботах 3. Слєпкань, Г. Бевза, Я. Грудьонова, Л. Голодюк, О. Скафи, I. Лов'янової, О. Чашечникової та ін. Проте поза увагою дослідників залишились питання предметно-практичної (маніпулятивної) діяльності учнів під час вивчення об’ємів геометричних тіл як основи для якісного сприймання й засвоєння змісту навчального матеріалу.

Мета статті - розкрити особливості організації вивчення об'ємів геометричних тіл на рівні стандарту в курсі геометрії 11 класу.

Виклад основного матеріалу. Розглянемо деякі особливості організації вивчення об'ємів геометричних тіл на рівні стандарту, а саме: 1) об'ємів многогранників; 2) об'ємів циліндра і конуса; 3) об'ємів кулі.

1. Об'єми многогранників. Під час вивчення з теми «Об'єми многогранників» необхідно ознайомити учнів з поняттям об'єму геометричної фігури, з формулами об'єму призми та об'єму піраміди й відповідними правилами та формувати вміння учнів знаходити об'єм призми й піраміди, використовувати об'єм як допоміжний елемент у розв'язуванні задач, зчитувати інформацію із зображення призми чи піраміди та позначених на ньому даних, виконувати допоміжні планіметричні рисунки $[1 ; 7 ; 15]$.

Для введення на уроці основних об’єктів засвоєння з цієї теми на рівні стандарту доцільно організувати практичну роботу під час якої ознайомити учнів зі способом вимірювання об'ємів за допомогою пересипання (переливання). На цьому уроці знадобиться таке обладнання: пустотілі прозорі макети прямих і похилих призм та пірамід 3 рівними й рівновеликими основами, що виступатимуть ємностями для пересипання (переливання); пісок (вода); таблиця з формулами площі многокутників; посібник із диференційованими завданнями за готовими рисунками [9] (чи роздатковий матеріал, що містить аналогічні рисунки).

На етап актуалізації базових знань і вмінь доцільно винести запитання для повторення та вправи для відновлення базових умінь $[1 ; 2 ; 6]$. Наведемо їх.

Запитання для повторення.

1. Яке геометричне тіло є многогранником?

2. Який многогранник є призмою, а який - пірамідою?

3. Які многокутники можуть лежать в основі призми? А в основі піраміди?

4. Чим відрізняється пряма призма від похилої призми?

5. Якими многокутниками є грані паралелепіпеда?

6. Чи є призмою прямокутний паралелепіпед?

7. Чи є правильною піраміда, в основі якої лежить прямокутний трикутник? 
Вправи для відновлення базових умінь учнів.

1. Демонструючи учням один за одним макети призм і пірамід, пропонуємо відповісти на запитання: «Чи є висотою даної призми (піраміди) іiї бічне ребро?»

2. Усні вправи за готовими рисунками [9].

На етапі вивчення нового матеріалу роботу учнів доцільно організувати в наступний спосіб $[1 ; 2 ; 13]$.

Пояснюємо учням, що кожне геометричне тіло має властивість займати певну частину простору. Таку властивість геометричного тіла називають об'ємом тіла.

Об'єми різних тіл можна порівнювати - одне тіло може займати більшу частину простору, аніж інше, або таку саму частину простору, або меншу частину простору. Якщо прийняти якесь тіло за мірку, а його об'єм - за одиницю вимірювання об'ємів, то об'єм будь-якого тіла можна виразити деяким додатним числом. У геометрії за мірку беруть куб, ребро якого має довжину, що дорівнює одиниці довжини. Об'єм такого куба приймають за одиницю вимірювання об'ємів.

Разом з учнями пригадуємо, як у 5-6 класі вимірювали об'єм прямокутного паралелепіпеда 3 ребрами $a, b$ i $c$. У результаті практичних дій тоді було отримано формулу об'єму прямокутного паралелепіпеда:

$$
V=a b c .
$$

3 цієї формули була виведена формула об'єму куба з ребром $a$ :

$$
V=a^{3} \text {. }
$$

Нагадуємо учням, що на початку 10 класу вони познайомилися й 3 іншими многогранниками - 3 призмами й пірамідами різних видів. Природно виникає запитання: «Як обчислювати об’єми таких многогранників?». Відповідь на це запитання пропонуємо знайти за допомогою експерименту.

Демонстраційний експеримент проводимо у декілька етапів.

I етап. Використовуємо прямокутний паралелепіпед з ребрами $a, b$ i $c$ та похилий паралелепіпед, в основі якого лежить прямокутник зі сторонами $a$ i $b$, а його висота дорівнює $c$ (рис. 1). Пересипанням піску 3 прямокутного паралелепіпеда у похилий паралелепіпед демонструємо факт рівності об’ємів таких многогранників.
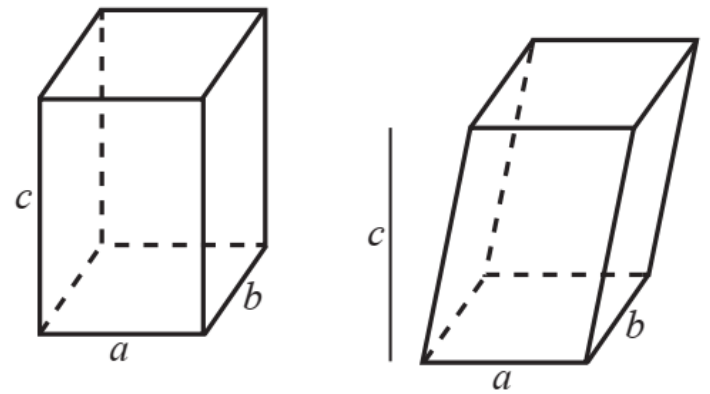

Рис. 1.

II етап. Використовуємо пряму призму (рис. 2, а), в основі якої лежить чотирикутник, рівновеликий з основою прямокутного паралелепіпеда, й висота якої дорівнює $c$. Разом 3 учнями 3'ясовуємо, що площі основ цих многогранників рівні. Пересипанням піску з похилого паралелепіпеда у пряму призму демонструємо факт рівності об'ємів таких многогранників.

III етап. Використовуємо похилу призму (рис. 2, б), висота якої дорівнює $c$ й в основі якої лежить чотирикутник, рівновеликий як 3 основою прямокутного паралелепіпеда, так і з основою прямої призми. Разом з учнями з'ясовуємо, що основи трьох многогранників, що розглядаються, мають рівні площі. Пересипанням піску 3 
похилого паралелепіпеда у похилу призму демонструємо факт рівності об'ємів таких многогранників.

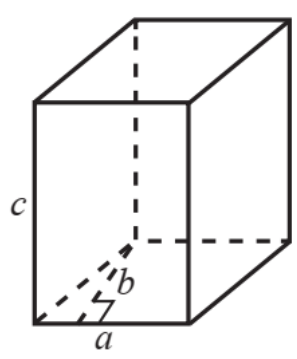

a)

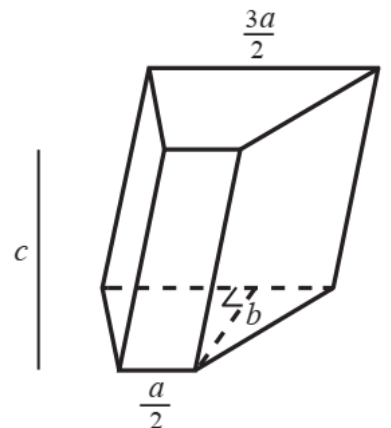

б)

Рис. 2.

IV етап. Використовуємо дві рівні прямі трикутні призми, висоти яких дорівнюють $c$, а основи $\epsilon$ прямокутними трикутниками з катетами $a$ i $b$ (рис. 3). Пересипанням піску 3 прямого паралелепіпеда в обидві прямі трикутні призми демонструємо факт того, що об’єм кожної з таких трикутних призм становить половину об'єму прямокутного паралелепіпеда.

$\mathbf{V}$ етап. Використовуємо дві рівні похилі трикутні призми, висоти яких дорівнюють $c$, а основи $є$ прямокутними трикутниками з катетами $a$ i $b$ (рис. 4). Пересипанням піску 3 двох прямих трикутних призм в обидві похилі трикутні призми демонструємо два факти: об’єм кожної з таких трикутних призм становить половину об'єму прямокутного паралелепіпеда; об’єми даних прямих і похилих трикутних призм є рівними.
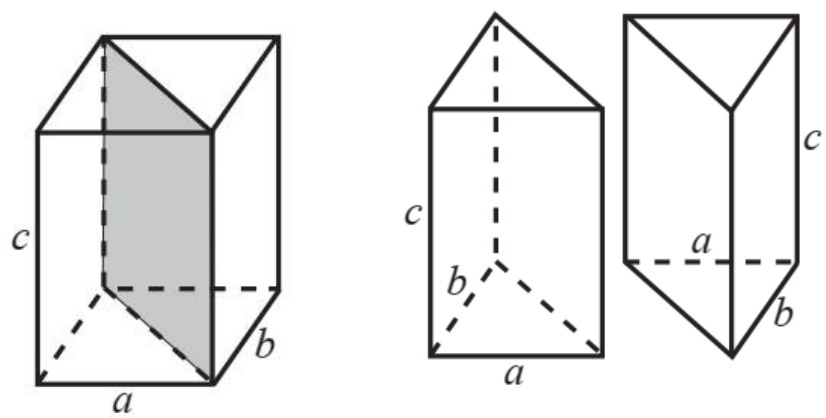

Рис. 3.

На базі отриманих емпіричних фактів формулюємо гіпотези:

- якщо призми мають рівні площі основ і рівні висоти, то їх об’єми рівні;

- якщо призми мають рівні висоти, а площі основ знаходяться у певному відношенні, то об’єми призм знаходяться у такому самому відношенні;

- для знаходження об’єму призми потрібно знати площу ії основи та висоту.
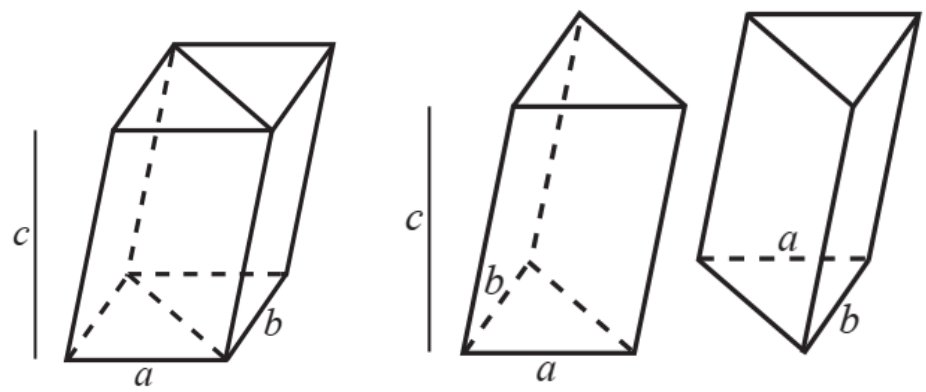

Рис. 4. 
Спираючись на формулу об'єму прямокутного паралелепіпеда, пропонуємо учням з'ясувати, як пов'язані між собою такі три величини - об'єм прямокутного паралелепіпеда, площа його основи та висота. Виходить: добуток $a b c$ є добутком площі $a b$ прямокутника основи даного паралелепіпеда та його висоти $c$ :

$$
V=a b \cdot c .
$$

Отже, якщо для даного прямокутного паралелепіпеда ввести позначення: $a b-S_{\text {осн }}$; $c-H$, то формулу його об'єму можна записати так:

$$
V=S_{\text {осн }} \cdot H \text {. }
$$

Міркуючи далі, разом з учнями з'ясовуємо, що чотирикутні призми, у тому числі й прямокутний паралелепіпед, які використовувались в експерименті, мають рівні об'єми, рівні площі основ та рівні висоти. Отже, об’єм кожної з них також можна обчислити за формулою:

$$
V=S_{\text {осн }} \cdot H .
$$

Об'єм кожної трикутної призми, що розглядалася в експерименті, становить половину об'єму відповідної призми, а площа іï основи - половину площі основи відповідної призми. Висоти є рівними. Отже:

$$
\begin{gathered}
\frac{1}{2} V=\frac{1}{2} S_{\mathrm{ocн}} \cdot H, \\
V=S_{\text {осн }} \cdot H .
\end{gathered}
$$

Ставимо запитання: «Чи не можна за такою самою формулою обчислити об'єм призми, основа якої - довільний многокутник?». Відповідаємо: «Оскільки многокутник основи можна розбити на трикутники, то, напевно, й призму можна розбити на трикутні призми. Тоді об'єм даної призми можна обчислити як суму об'ємів трикутних призм. Якщо записати відповідні співвідношення та виконати перетворення, то прийдемо до тієї самої формули об’єму призми».

Разом з учнями формулюємо правило.

Правило 1. Щоб знайти об'єм призми, треба обчислити добуток двох множників - площі основи призми та довжини висоти призми.

VI етап. На даному етапі експерименту встановлюємо залежність між об'ємом призми та об'ємом піраміди (рис. 5), яка має основу, рівновелику з основою даної призми, й висоту, що дорівнює висоті призми. При пересипанні піску із піраміди в призму виходить, що об'єм піраміди становить третину об'єму відповідної призми. Повторюючи експеримент з іншою пірамідою та відповідною ій призмою, отримуємо підтвердження цього факту.
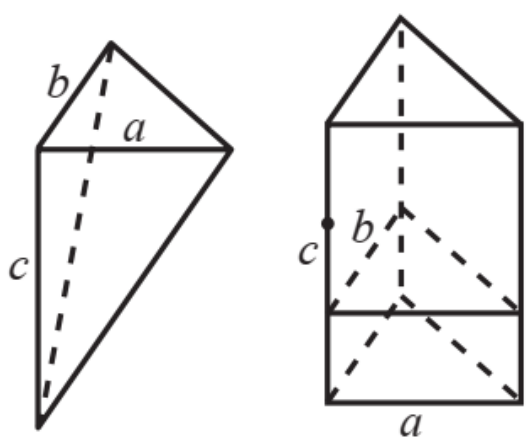

Рис. 5.

Робимо висновок, що формулу об’єму піраміди можна подати у вигляді:

$$
V=\frac{1}{3} S_{\text {осн }} \cdot H
$$

Разом з учнями формулюємо друге правило. 
Правило 2. Щоб знайти об'єм піраміди, треба обчислити третину добутку двох множників - площі основи піраміди та довжини висоти піраміди.

Пропонуємо учням записати у зошитах обидва правила й оформити записи так, як наведено у таблиці 1.

\begin{tabular}{|c|c|}
\hline Правило 1. & Правило 2. \\
Щоб знайти & Щоб знайти \\
об'єм призми, & об'єм піраміди, \\
треба обчислити & треба обчислити \\
добуток & третину добутку \\
двох множників: & двох множників: \\
- площі основи призми; & $-\quad$ площзі основи піраміди; \\
- довжини висоти призми: & $-\quad$ довжини висоти піраміди: \\
$V=S_{\text {осн }} \cdot H$ & $V=\frac{1}{3} S_{\text {осн }} \cdot H$ \\
\hline
\end{tabular}

Таблиця 1

Бажано, щоб у зошитах учні виділили різними кольорами істотні моменти правил. Формули краще записати червоною пастою.

Для закріплення пропонуємо учням відповісти на запитання:

1) чи правильно, що об'єм призми дорівнює добутку довжин трьох іiі ребер?

2) чи правильно, що об’єм призми в декілька разів більший за площу його основи?

$(H i)$

(Ні. Об'єм і площз - величини різних розмірностей);

3) чи можуть мати рівні об'єми дві призми з рівними висотами, якщо основа однієї 3 них - квадрат, а основа іншої - прямокутник?

(Так. Наприклад, якщзо в основі одної призми лежить квадрат зі стороною 4, а в основі іншої призми - прямокутник із сторонами 2 i 8 , то плоші основ таких призм с рівними. Оскільки в них і висоти є рівними, то рівними є й об'єми);

4) чи можуть мати рівні об’єми дві призми, якщо їх висоти відносяться, як $1: 2$ ?

(Так, якщзо площиі їх основ відносяться, як $2: 1)$;

5) чи правильно, що об'єм піраміди дорівнює площі ії основи, помноженій на третину висоти піраміди?

$($ Так).

Формування вмінь учнів застосовувати нові знання проводимо на базі завдань 10.1 (задачі I - II стовпчиків), 10.2 (задачі I - II стовпчиків), 10.3 (задачі I - II стовпчиків) і 10.4 (задачі I стовпчика) посібника із диференційованими завданнями за готовими рисунками [9].

Оформлення розв'язання задач завдання 10.1.

До задачі № 266 записи учнів можуть бути наступними.

Даний паралелепіпед - прямокутний. Значить, $A A_{1}$ - його висота.

$A K=K A_{1}=A D=A B=3 . A A_{1}=2 A B=6$.

$A B C D$ - квадрат.

$S_{A B C D}=A B^{2}$.

$S_{A B C D}=3^{2}=9$.

$V=S_{\text {осн }} \cdot H$.

$V=9 \cdot 6=54$.

Відповідь: 54 куб. од. 
Оформлення розв'язання задач завдання 10.2.

До задачі № 279 записи учнів можуть бути наступними.

Дана призма $є$ прямою призмою, значить ії бічне ребро є ії̈ висотою.

$A B=B C=C D=D M=A M$.

$P_{A B C D}=5 A B$. Звідси $A B=3 . A D=6$.

Значить, $A B=B C=C D=A_{1} B_{1}=B_{1} C_{1}=C_{1} D_{1}=3, A D=A_{1} D_{1}=6$.

$\triangle A B M=\triangle C B M=\triangle C D M-$ рівносторонні.

$S_{\triangle A B C}=\frac{A B^{2} \sqrt{3}}{4}=\frac{9 \sqrt{3}}{4}$.

$S_{A B C D}=3 S_{\triangle A B C}=\frac{27 \sqrt{3}}{4}$.

$V=S_{\text {ocн }} \cdot H$.

$27 \sqrt{3}=\frac{27 \sqrt{3}}{4} \cdot H$.

$H=4$.

Значить, $A A_{1}=B B_{1}=C C_{1}=D D_{1}=4$.

Biдnовiдb: $3 ; 4 ; 6$.

Оформлення розв'язання задач завдання 10.3.

До задачі № 289 записи учнів можуть бути наступними.

Дана піраміда $є$ правильною, значить $\triangle A B C$ - рівносторонній.

$M N \| A B$, значить $\triangle M N C \sim \triangle A B C$.

$M C: A C=2: 3$, значить $S_{\triangle M N C}: S_{\triangle A B C}=4: 9$.

$S_{\triangle A B C}=\frac{9 S_{\triangle M N C}}{4}=\frac{9 \sqrt{3}}{4}$.

$S_{\triangle A B C}=\frac{A B^{2} \sqrt{3}}{4}$, значить, $A B=3$.

$M N=\frac{2}{3} A B=2$.

$M H=1$.

$P H=M H=3, P H=4$.

$V=S_{\mathrm{oCH}} \cdot H$.

$V=\frac{1}{3} \cdot \frac{9 \sqrt{3}}{4} \cdot 4=3 \sqrt{3}$.

Відповідь: $3 \sqrt{3}$ куб. од.

Оформлення розв'язання задач завдання 10.4.

До задачі № 299 записи учнів можуть бути наступними.

$V=\frac{1}{3} S_{\text {осн }} \cdot H$. Значить, $H=\frac{3 V}{S_{\text {осн }}}$.

Знайдемо $S_{\text {осн }}$.

$A B C D$ - паралелограм.

$\triangle A B C=\triangle C D A . S_{\triangle A B C}=S_{\triangle C D A}$, значить $S_{A B C D}=2 S_{\triangle A D C}$.

$$
\begin{aligned}
& \frac{C H}{H K}=2,5 . H K=C H: 2,5=15: 2,5=6 . \\
& A C=C H=H K=15+6=21 .
\end{aligned}
$$


Нехай $A D=x$, тоді $C D=7+x$.

Виразимо $D H$ за теоремою Піфагора $3 \Delta A H D$ і $\triangle C H D$ та прирівняємо отримані вирази:

$(7+x)^{2}-15^{2}=x^{2}-6^{2}$

$(7+x)^{2}-x^{2}=15^{2}-6^{2}$,

$(7+x-x)(7+x+x)=(15-6)(15+6)$,

$7 \cdot(7+2 x)=9 \cdot 21$,

$x=10$.

Отже, $A D=10, C D=17, A C=21$.

$P_{\triangle A D C}=10+17+21=48, p=24$.

За формулою Герона, $S_{\triangle A D C}=\sqrt{p(p-A D)(p-C D)(p-A C)}$. Тоді:

$S_{\triangle A D C}=\sqrt{24(24-10)(24-17)(24-21)}=\sqrt{4 \cdot 2 \cdot 3 \cdot 2 \cdot 7 \cdot 7 \cdot 3}=84$.

$S_{A B C D}=168$.

$H=\frac{3 \cdot 896}{168}=16$.

Площина $Z H B$ перпендикулярна до площини основи, так як містить висоту піраміди.

Bidnoвidb: 16; площина ZHB перпендикулярна до площини основи.

Для підведення підсумків уроку разом з учнями повторюємо:

- формулу об'єму призми;

- формулу площі бічної поверхні призми;

- формулу об'єму піраміди;

- формулу бічної поверхні піраміди;

- правило знаходження об'єму призми;

- правило знаходження об'єму піраміди.

2. Об'єми циліндра й конуса. Новий навчальний матеріал тем «Об'єми циліндра» і «Об'єм конуса», на нашу думку, варто винести на один урок, під час якого варто ознайомити учнів із формулами об'єму циліндра й конуса та відповідними правилами [1; 15], зі способом вимірювання об'ємів за допомогою пересипання (переливання), а також формувати в учнів вміння знаходити об'єми циліндра й конуса, зчитувати інформацію із зображення циліндра й конуса та позначених на ньому даних, виконувати допоміжні планіметричні рисунки.

Для організації такого уроку знадобиться таке обладнання: пустотілі прозорі макети прямої $n$-кутної призми, циліндра й конуса, що виступатимуть ємностями для пересипання (переливання); пісок (вода); посібник із диференційованими завданнями за готовими рисунками [9] (чи роздатковий матеріал, що містить аналогічні рисунки).

Для ознайомлення учнів 3 новим матеріалом доцільно організувати демонстраційний експеримент аналогічно до того, як це робилося на попередньому уроці. Демонстраційний експеримент проводимо у декілька етапів.

I етап. Використовуємо пустотілі прозорі макети прямої $n$-кутної призми i циліндра $з$ рівними висотами й такими основами, що радіус основи циліндра дорівнює радіусу кола, описаного навколо многокутника основи призми (рис. 6). Разом з учнями з'ясовуємо, що площі основ призми і циліндра не є рівними, але відрізняються не значно. Пересипанням піску з призми у циліндр демонструємо факт того, що об'єми призми і циліндра також не є рівними, але відрізняються не значно.

II етап. На зображенні кола із вписаним у нього $n$-кутником основи даної призми показуємо учням процедуру подвоєння сторін $n$-кутника (рис. 7). Разом з учнями формулюємо припущення: «При подальшому подвоєнні сторін $n$-кутника його контур все більше наближатиметься до кола. Отже, периметр многокутника все більше наближатиметься до довжини кола, а площа многокутника - до площі даного круга». 

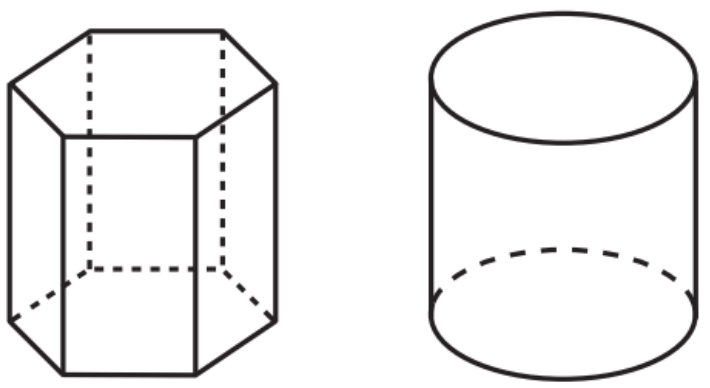

Рис. 6

III етап. Міркуючи далі, приходимо до висновку, що об’єм циліндра майже не відрізнятиметься від об'єму прямої призми із таким многокутником основи. Напевно, об'єм циліндра можна обчислювати за такою самою формулою, як і об'єм призми:

$$
V=S_{\text {осн }} \cdot H \text {. }
$$

Разом з учнями формулюємо правило.

Правило 1. Щоб знайти об'єм циліндра, треба обчислити добуток двох множників - площі основи циліндра та довжини висоти циліндра.
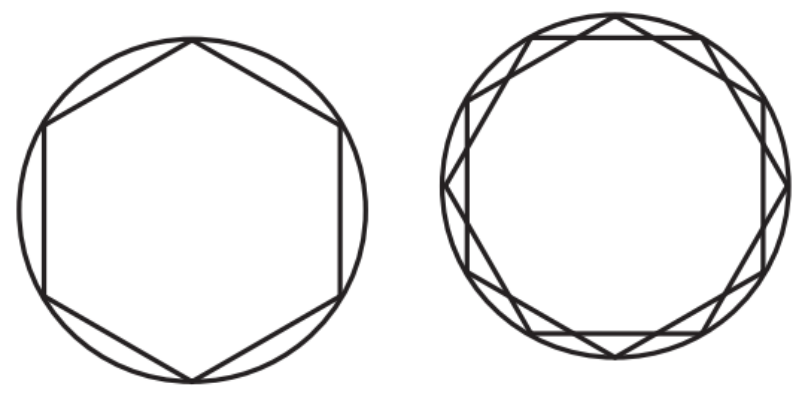

Рис. 7.

IV етап. Використовуємо циліндр і конус з рівними основами й висотами (рис. 8). При пересипанні піску із конуса в циліндр виходить, що об'єм конуса становить третину об'єму відповідного циліндра.
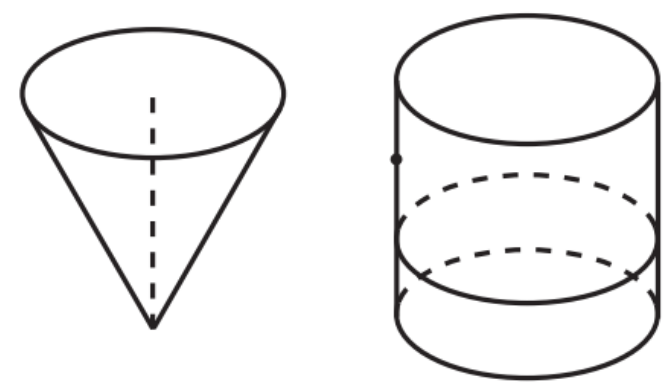

Рис. 8.

Робимо висновок, що формулу об’єму піраміди можна подати у вигляді:

$$
V=\frac{1}{3} S_{\text {осн }} \cdot H
$$

Разом з учнями формулюємо друге правило.

Правило 2. Щоб знайти об'єм конуса, треба обчислити третину добутку двох множників - площі основи конуса та довжини висоти конуса. 
Пропонуємо учням записати у зошитах обидва правила й оформити записи так, як наведено у таблиці 2.

Таблиця 2

\begin{tabular}{|c|c|}
\hline Правило 1. & Правило 2. \\
Щоб знайти & Щоб знайти \\
об'єм циліндра, & об'єм конуса, \\
треба обчислити & треба обчислити \\
добуток & третину добутку \\
двох множників: & двох множників: \\
- площі основи циліндра; & - площі основи конуса; \\
- довжини висоти циліндра: & - довжини висоти конуса: \\
$V=S_{\text {осн }} \cdot H$ & $V=\frac{1}{3} S_{\text {осн }} \cdot H$ \\
\hline
\end{tabular}

При цьому бажано, щоб у зошитах учні виділили різними кольорами істотні моменти даних записів. Формули краще записати червоною пастою.

Для закріплення пропонуємо учням відповісти на запитання:

1) чи правильно, що об'єм циліндра можна обчислити за формулою

$$
V=\pi R^{2} H ?
$$

$($ Так).

2) чи правильно, що об’єм конуса можна обчислити за формулою

$$
V=\frac{1}{3} \pi R^{2} H ?
$$

$($ (Так).

3) чи правильно, що об’єм циліндра дорівнює добутку довжини кола основи і твірної?

4) чи правильно, що площу бічної поверхні конуса можна обчислити як третину добутку площі основи й висоти конуса?

5) чи знайдемо об’єм циліндра, помноживши площу його бічної поверхні на радіус основи?

(Hi, оскільки

$$
\left.S_{\text {бп }} \cdot R=2 \pi R H \cdot R=2 \pi R^{2} H \neq V\right) \text {. }
$$

Формування вмінь учнів застосовувати нові знання проводимо на базі завдань 11.1 (задачі I - II стовпчиків), 11.2 (задачі I - II стовпчиків), 11.3 (задачі I - II стовпчиків) i 11.4 (задачі I стовпчика) посібника із диференційованими завданнями за готовими рисунками [9].

Оформлення розв'язання задач завдання 11.1.

До задачі № 306 записи учнів можуть бути наступними.

Циліндр утворено обертанням прямокутника $A O O_{1} B$.

$C O O_{1} D$ - прямокутник, у який перейшов прямокутник $A O O_{1} B$ при повороті.

Утворився прямокутник $A B D C$.

$A C=2 R, A B=D C=H=6$.

$\triangle A C D$ - прямокутний, $\angle A C D=90^{\circ}, \angle A D C=45^{\circ}$.

Значить $\angle C A D=45^{\circ}$, а $\triangle A C D$ - рівнобедрений.

$A C=D C=6$.

$R=3$.

$V=\pi R^{2} H$. 
$V=\pi \cdot 3^{2} \cdot 6=54 \pi$.

Відповідь: $54 \pi$ куб. од.

Для підведення підсумків уроку разом з учнями повторюємо:

- формулу об'єму циліндра;

- формулу площі бічної поверхні циліндра;

- формулу об'єму конуса;

- формулу площі бічної поверхні конуса;

- правило знаходження об'єму циліндра;

- правило знаходження об’єму конуса.

3. Об'єм кулі. Вивчення нового навчального матеріалу цієї теми доцільно організувати за аналогічною методичною схемою. На першому уроці доцільно поставити таку мету: ознайомити учнів 3 формулою об’єму кулі та зі способом вимірювання об'ємів за допомогою пересипання (переливання); формувати вміння учнів знаходити об'єм кулі, використовувати об'єм як допоміжний елемент у розв'язуванні задач, зчитувати інформацію із зображення кулі та позначених на ньому даних, виконувати допоміжні планіметричні рисунки.

На цьому уроці знадобиться наступне обладнання: пустотілі прозорі макети конуса і півкулі, що виступатимуть ємностями для пересипання (переливання), пісок (вода), посібник із диференційованими завданнями за готовими рисунками [9] (чи роздатковий матеріал, що містить аналогічні рисунки).

Для ознайомлення учнів 3 новим матеріалом доцільно організувати демонстраційний експеримент аналогічно до того, як це робилося на попередньому уроці. Демонстраційний експеримент і відповідні міркування, що приведуть до формули об'єму кулі, проводимо в наступний спосіб.

Використовуємо макети півкулі та конуса, у якого радіус основи й висота мають таку саму довжину, що й радіус півкулі (рис. 9). Пересипаючи пісок із конуса в півкулю, одержуємо, що півкуля заповнилась частково. Якщо пересипати пісок із конуса ще раз, півкуля заповниться повністю. Отже, об’єм півкулі вдвічі більший за об'єм відповідного конуса.
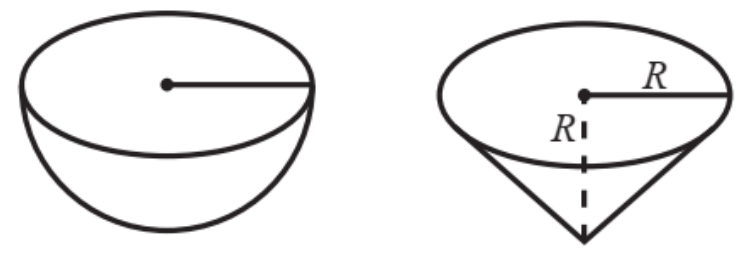

Рис. 9.

Об’єм конуса обчислюють за формулою $V=\frac{1}{3} \pi R^{2} H$. У даного конуса $H=R$, значить, його об'єм можна обчислити за формулою: $V=\frac{1}{3} \pi R^{3}$.

Отже, формулу об'єму півкулі можна подати у вигляді: $V=\frac{2}{3} \pi R^{3}$.

Об’єм кулі вдвічі більший за об'єм півкулі, тому формула об'єму кулі має вигляд:

$$
V=\frac{4}{3} \pi R^{3}
$$

Разом з учнями оформляємо довідникову таблицю 3. 


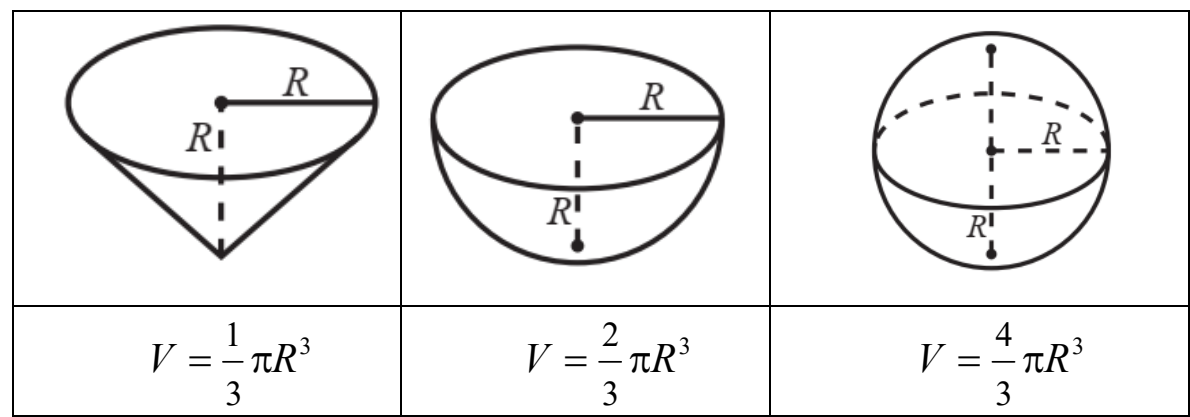

Таблиия 3

Для закріплення пропонуємо учням відповісти на запитання.

1. Чи правильно, що об’єм кулі у чотири рази більший за об’єм конуса?

(Відповідь залежить від того, який розглядається конус);

2. Чи правильно, що об’єм кулі збільшиться у 9 разів, якщо ії радіус збільшити у 3 рази?

$(\mathrm{Hi})$.

3. Чи можна використати площу поверхні кулі для обчислення об'єму кулі?

(Так. За площею сфери можна знайти радіус кулі,

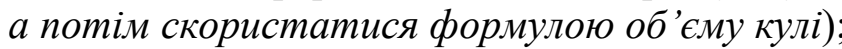

4. Чи правильно, що коефіцієнт у формулі об’єму кулі у 3 рази менший від коефіцієнта у формулі площі сфери?

(Tak).

5. Чи можуть об’єм кулі та площа ії поверхні мати одне й те саме чисельне значення?

6. Чи може об’єм кулі дорівнювати площі їі поверхні?

(Так. Наприклад, якщзо $R=3$ ).

(Нi. Об'єм вимірюється в кубічних одинииях,

а площса - у квадратних одинииях).

7. Відомо, що куля має об'єм $288 \pi$ і площу поверхні $144 \pi$. Чи правильно, що об'єм кулі у два рази більший за площу іï поверхні?

(Hi).

Формування вмінь учнів застосовувати нові знання розпочинаємо з наступної задачі.

Задача. Знайдіть попарні відношення об'ємів циліндра, кулі й конуса, якщо діаметри й висоти циліндра й конуса дорівнюють діаметру кулі.

Розв'язання.

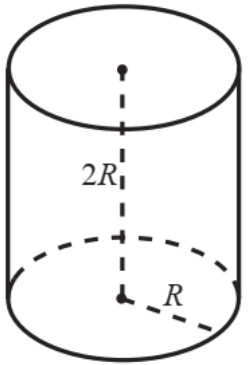

$V=\pi R^{2} \cdot 2 R$

$V=2 \pi R^{3}$

$V=\frac{6}{3} \pi R^{3}$

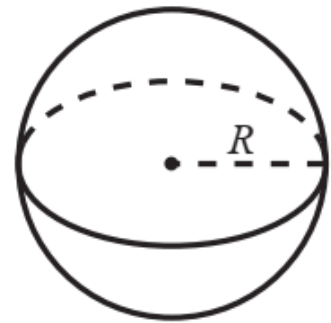

$V=\frac{4}{3} \pi R^{3}$

$V=\frac{4}{3} \pi R^{3}$

$V=\frac{4}{3} \pi R^{3}$

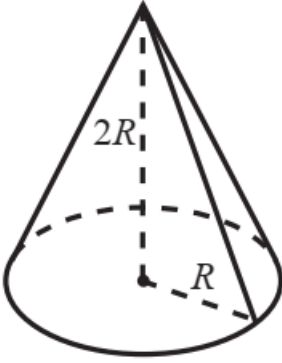

$V=\frac{1}{3} \pi R^{3} \cdot 2 R$

$V=\frac{2}{3} \pi R^{3}$

$V=\frac{2}{3} \pi R^{3}$ 


$$
V=3 \cdot\left(\frac{2}{3} \pi R^{3}\right) \quad V=2 \cdot\left(\frac{2}{3} \pi R^{3}\right) \quad V=1 \cdot\left(\frac{2}{3} \pi R^{3}\right)
$$

Якщо ввести коефіцієнт пропорційності $k=\frac{2}{3} \pi R^{3}$, то одержимо:

$$
V=3 \cdot k \quad V=2 \cdot k \quad V=1 \cdot k
$$

Отже, відношення об’ємів даних циліндра, кулі й конуса становить $3: 2: 1$.

Відповідь: $3: 2: 1$.

Подальшу роботу проводимо на базі завдань 11.5 (задачі I - II стовпчиків), 11.6 (задачі I - II стовпчиків) і 11.7 (задачі I - II стовпчиків) посібника із диференційованими завданнями за готовими рисунками [9].

Оформлення розв'язання задач завдання 11.5.

До задачі № 344 записи учнів можуть бути наступними.

Кулю отримано повертанням круга з центром у т. $O$ і радіусом $O C=R$.

$B C=2 R, \mathrm{QO}=2-\sqrt{3}, B Q=\mathrm{R}-2+\sqrt{3}, C Q=R+2-\sqrt{3}$.

$\angle C A B=90^{\circ}$ (як вписаний, що спирається на діаметр).

$\triangle C A B$ - прямокутний, $\angle C A B=90^{\circ}, \angle A C B=30^{\circ}, \angle C B A=60^{\circ}$.

$\angle B A Q=\angle C A Q=90^{\circ}: 2=45^{\circ}$.

Виразимо за теоремою синусів $A Q$ в $\triangle B A Q$ і $\triangle C A Q$.

$\triangle B A Q: \frac{A Q}{\sin 60^{\circ}}=\frac{B Q}{\sin 45^{\circ}}, A Q=\frac{B Q \sin 60^{\circ}}{\sin 45^{\circ}}, A Q=\frac{B Q \sqrt{3}}{\sqrt{2}}$.

$\triangle C A Q: \frac{A Q}{\sin 30^{\circ}}=\frac{Q C}{\sin 45^{\circ}}, A Q=\frac{Q C \sin 30^{\circ}}{\sin 45^{\circ}}, A Q=\frac{Q C}{\sqrt{2}}$.

Складемо та розв'яжемо рівняння.

$$
\begin{aligned}
& \frac{B Q \sqrt{3}}{\sqrt{2}}=\frac{Q C}{\sqrt{2}}, \\
& B Q \sqrt{3}=Q C, \\
& (R-2+\sqrt{3}) \sqrt{3}=R+2-\sqrt{3}, \\
& R \sqrt{3}-2 \sqrt{3}+3=R+2-\sqrt{3}, \\
& R(\sqrt{3}-1)=\sqrt{3}-1, \\
& R=1 . \\
& V=\frac{4}{3} \pi R^{3}, \\
& V=\frac{4}{3} \pi .
\end{aligned}
$$

Відповідь: $\frac{4}{3} \pi$ куб. од.

Оформлення розв'язання задач завдання 11.6.

До задачі № 352 записи учнів можуть бути наступними.

Кулю отримано повертанням круга з центром у т. $O$ і радіусом $O A=R$. $V=\frac{4}{3} \pi R^{3}$. 
Складемо і розв'яжемо рівняння:

$$
\begin{aligned}
& \frac{4}{3} \pi R^{3}=\frac{1372 \pi \sqrt{3}}{27}, \\
& R^{3}=\frac{343 \cdot 3 \sqrt{3}}{27}, R=\frac{7 \sqrt{3}}{3} .
\end{aligned}
$$

$\triangle A B C: A C=8, B C=5, \angle A C B=60^{\circ}$.

$A B^{2}=A C^{2}+B C^{2}-2 \cdot A C \cdot B C \cdot \cos 60^{\circ}$ (за теоремою косинусів).

$A B^{2}=8^{2}+5^{2}-2 \cdot 8 \cdot 5 \cdot \frac{1}{2}=89-40=49$.

$A B=7$.

$A K=B K=\frac{7}{2}$.

$\triangle A O K: A O=\frac{7 \sqrt{3}}{3}, \mathrm{AK}=\frac{7}{2}, \angle A K O=90^{\circ}$.

$A O^{2}=A K^{2}+O K^{2}$ (за теоремою Піфагора).

$O K^{2}=A O^{2}-A K^{2}$.

$$
\begin{aligned}
O K^{2} & =\left(\frac{7 \sqrt{3}}{3}\right)^{2}-\left(\frac{7}{2}\right)^{2}=\frac{49}{3}-\frac{49}{4}=\frac{49}{12}=\frac{49 \cdot 3}{36} . \\
O K & =\frac{7 \sqrt{3}}{6} .
\end{aligned}
$$

Biдnовідb: $\frac{7 \sqrt{3}}{6}$.

На етапі застосування нових знань пропонуємо учням серію прикладних задач (КОзадач) [3; 8; 15]. На уроці для їх опрацювання доцільно організувати коментоване розв'язування при роботі одного учня біля дошки. Для такого виду роботи не обов'язково використовувати усі наведені нижче задачі. Деякі 3 них можна запропонувати сильним учням для індивідуального розв'язування.

1. Скільки квадратних метрів оцинкованого заліза знадобиться для виготовлення бака, що має форму прямокутного паралелепіпеда? Відомо, що основа бака - прямокутник розмірами $1,8 \mathrm{~m} \times 1,2 \mathrm{м}$ і бак вміщує 2700 л води.

2. Як із шести рівних відрізків утворити чотири рівносторонніх трикутники?

$\left(9,66 M^{2}\right)$

(Утворити правильну трикутну піраміду).

3. Скільки тканини завширшки 0,6 м знадобиться для намету, який має форму правильної чотирикутної піраміди, якщо сторона основи становить 3 м, а апофема - 5 м? (Витрати тканини на шви складають 8\% площі бічної поверхні піраміди).

4. Одна колода має товщину, яка в три рази більша за товщину іншої колоди, але має довжину, яка в три рази менша від довжини іншої колоди. Знайдіть відношення їх мас. Якою має бути довжина другої колоди, щоб їх маси були рівні?

(3 : $1 ;$ у дев'ять разів більша).

5. Свинцеву кулю діаметром 6 см сплющили у круглий лист завтовшки 1,8 мм. Визначте діаметр листа. 
Для підведення підсумків уроку разом з учнями повторюємо:

- формулу об'єму півкулі;

- формулу об'єму кулі;

- формулу площі сфери;

- формулу площі круга;

- формулу довжини кола.

Висновки. Загалом, застосування компетентнісного підходу до організації вивчення об'ємів деяких геометричних тіл (многогранників, циліндра, конуса, кулі) в старшій профільній школі на рівні стандарту потребує створення системи спеціальних завдань та специфічної методики викладу навчального матеріалу та його закріплення $[11 ; 12 ; 14]$. Вдалий добір математичних, міжпредметних, практичних й прикладних задач та дидактично виважена організація їх розв'язування є запорукою ефективного навчання учнів стереометрії на рівні стандарту, у результаті якого в учнів формуються міцні знання, навички та вміння $з$ даної теми, а також удосконалюються важливі якості особистості.

\section{Список використаної літератури.}

1. Бурда М. І. Геометрія : [підруч. для 11 кл. загальноосвіт. навч. закладів; академічний та профільний рівні] / М. І. Бурда, Н. А. Тарасенкова, І. М. Богатирьова, О. М. Коломієць, З. О. Сердюк. - К. : Видавничий дім «Освіта», 2013. - 304 с.

2. Бурда М. І. Теоретико-методичні вимоги до змісту шкільних підручників з математики / М. І. Бурда, Н. А. Тарасенкова // Проблеми сучасного підручника : зб. наук. праць / [ред. кол.; голов. ред. О. М. Топузов]. - К. : Педагогічна думка, 2016. - Вип. 17. - С. 32-40.

3. Компетентнісні контрольні роботи з геометрії для 11 класу: [навч.-метод. посіб.] / Н. А. Тарасенкова, М. І. Бурда, І. М. Богатирьова, О. М. Коломієць, 3. О. Сердюк; за ред. Н. А. Тарасенкової. - Черкаси: Вид. Чабаненко, 2017. - $24 \mathrm{c}$.

4. Сердюк 3. О. Формування прийомів розумової діяльності учнів у процесі вивчення математики в школах і класах суспільно-гуманітарного напряму : дис. ... канд. пед. наук : 13.00 .02 «Теорія та методика навчання (математика)»/ Зоя Олексіївна Сердюк. - Черкаси, 2011. -245 с.

5. Тарасенкова Н. А. Активизация познавательной деятельности учащихся в условиях лекционнопрактической системы обучения математике в школе: дис. ... канд. пед. н. : 13.00 .02 / Тарасенкова Нина Анатольевна. - Киев, 1991. - 211 с.

6. Тарасенкова Н. А. Візуальний супровід побудови перерізів многогранників у підручнику / Н. А. Тарасенкова // Science and education a new dimension (Budapest); Chief Honorary Editor N. Tarasenkova. - 2017. - V (59), Issue: 134. - pp. 49-54.

7. Тарасенкова Н. А. Діалог під час усного розв'язування задач на уроці геометрії / Н. А. Тарасенкова // Вісник Черкаського університету. Серія «Педагогічні науки». - Випуск № 8 (341). - Черкаси: Вид. від. ЧНУ ім. Б. Хмельницького, 2015. - С. 43-49.

8. Тарасенкова Н.А. Експрес-контроль 3 геометрії для 11 класу (рівень стандарту): [навч.-метод. посіб.] / Н.А. Тарасенкова, М.І. Бурда, І.М. Богатирьова, О.П. Бочко, О.М. Коломієць, З.О. Сердюк; за ред. Н.А. Тарасенкової, М.І. Бурди. - К. : Видавничий дім «Освіта», 2012. - 72 с. Гриф МОН України «Схвалено».

9. Тарасенкова Н. А. Елементи стереометрії в основній школі: Диференційовані завдання за готовими рисунками для 9 класу. - Харків: Веста: Видавництво “Ранок”, 2002. - 80 с.

10. Тарасенкова Н. А. Задачний підхід до професійно спрямованого навчання математики у профільній школі / Н. А. Тарасенкова, І. В. Лов'янова // Вісник Черкаського університету Серія «Педагогічні науки». - Випуск № 26 (359). - Черкаси: Вид. від. ЧНУ ім. Б.Хмельницького, 2015. - С. 3-10.

11. Тарасенкова Н. А. Засоби перевірки математичної компетентності в основній школі / Н. А. Тарасенкова, І. М. Богатирьова, О. М. Коломієць, 3. О. Сердюк // Science and education a new dimension / Chief Honorary Editor: N. Tarasenkova. - III (26), Issue: 71. - Budapest: SCASPEE, 2015. P. 21-25.

12. Тарасенкова Н. Компетентнісний підхід у навчанні математики: теоретичний аспект / Н. Тарасенкова // Математика в рідній школі. - 2016. - № 11 (179). - С. 26-30.

13. Тарасенкова Н. А. Організація вступного уроку під час вивчення теми «Взаємне розміщення двох площин у просторі» / Н. А. Тарасенкова, 3. О. Сердюк // Вісник Черкаського університету : [№ 11 : серія Педагогічні науки]. - Черкаси: вид. від. ЧНУ ім. Б.Хмельницького, 2016. - С. 97-104. 
14. Тарасенкова Н. А. Організація навчання математики у старшій профільній школі : монографія / Н. А. Тарасенкова, І. А. Акуленко, І. В. Лов’янова, 3. О. Сердюк. - Черкаси: Видавець ФОП Гордієнко, 2017. -212 c.

15. Тарасенкова Н.А. Самостійні та контрольні роботи з геометрії для 11 класу (рівень стандарту): [навч.метод. посіб.] / Н.А. Тарасенкова, М.І. Бурда, І.М. Богатирьова, О.П. Бочко, О.М. Коломієць, 3.О. Сердюк; за ред. Н.А. Тарасенкової, М.І. Бурди. - К. : Видавничий дім «Освіта», 2012. - 48 с. Гриф МОН України «Схвалено».

\section{References.}

1. Burda, M., Tarasenkova, N., Bogatyryova, I., Kolomiyets, O. \& Serdiuk Z. (2013) Geometry: [textbook for the 11th form of general education institutions; Academic and profile levels]. K.: Publishing House «Osvita». 304 p. (in Ukr.).

2. Burda, M. \& Tarasenkova, N. (2016). Theoretical and methodical requirements for the contents of school textbooks on mathematics. Problems of the modern textbook: a collection of scientific works. - K.: Pedagogichna dumka. Issue 17, 32-40. (in Ukr.).

3. Tarasenkova, N., Burda, M., Bohatyryova, I., Kolomiyets, O. \& Serdiuk Z. (2017) Competency control works on geometry for class 11: [tutorial manual]; ed. N. Tarasenkova. Cherkasy: Publisher Chabanenko. 24 p. (in Ukr.).

4. Serdiuk, Z. O. (2011) Formation of methods of mental activity of students in the process of studying mathematics in schools and classes of the social and humanitarian direction: dissertation ... candidate of pedagogical sciences: 13.00.02 «Theory and methods of teaching (mathematics)». Cherkasy. 245 p. (in Ukr.)

5. Tarasenkova, N. (1991) Activization of the cognitive activity of students in the conditions of the lecturepractical system of teaching mathematics in school: dissertation ... candidate of pedagogical sciences: 13.00.02. Kiev. 211 p. (in Russ).

6. Tarasenkova, N. (2017) Visual support for the construction of cross sections of polyhedra in the textbook. Science and education a new dimension (Budapest); Chief Honorary Editor N. Tarasenkova. V (59), Issue: 134, 49-54. (in Ukr.)

7. Tarasenkova, N. (2015) Dialogue during the Oral Solving of Problems in the Lesson of Geometry. Bulletin of the Cherkasy University. Series «Pedagogical Sciences». Issue 8 (341). Cherkasy: Publishing Department of Cherkasy National University named Bohdan Khmelnitsky, 43-49. (in Ukr.)

8. Tarasenkova, N., Burda, M., Bogatyreva, I., Bochko, O., Kolomiets, O. \& Serdiuk, Z. (2012) Geometry Express Control for Grade 11 (Standard Level): [Tutorial]; ed. N. Tarasenkova, M Burda. - K.: Publishing House «Education». 72 p. Grif of the Ministry of Education and Science of Ukraine «Approved».(in Ukr.)

9. Tarasenkova, N. (2002) Elements of stereometry in the primary school: Differentiated tasks for ready-made drawings for the 9th form. Kharkiv: Vesta: Publishing House «Ranok». 80 p. (in Ukr.)

10. Tarasenkova, N. \& Lovyanova, I. (2015) Appropriate approach to professionally directed mathematics education in profile school. «Visnyk of the University of Cherkasy : Series «Pedagogical sciences». - Issue 26 (359). Cherkassy: Publishing Department of Cherkasy National University named Bohdan Khmelnitsky, 3-10. (in Ukr.)

11. Tarasenkova, N., Bogatyreva, I., Kolomiyets, O. \& Serdiuk, Z. (2015) Means of checking mathematical competence in the basic schoo.l Science and education a new dimension. Chief Honorary Editor: N. Tarasenkova. III (26), Issue: 71. Budapest: SCASPEE, 21-25. (in Ukr.)

12. Tarasenkova, N. (2016) Competence approach in teaching mathematics: theoretical aspect. Mathematics in native school. No. 11 (179), 26-30. (in Ukr.)

13. Tarasenkova, N. \& Serdiuk, Z. (2016) Organization of the introductory lesson during the study of the topic "Mutual placement of two planes in space». "Visnyk of the Cherkasy University»: [No. 11: Series of Pedagogical Sciences]. Cherkassy: Publishing Department of Cherkasy National University named Bohdan Khmelnitsky, 97-104. (in Ukr.)

14. Tarasenkova, N., Akulenko, I., Lovyanova, I. \& Serdiuk, Z. (2017) Organization of studying mathematics at the senior profile school: monograph. Cherkasy: Publisher FOP Gordienko. 212 p. (in Ukr.)

15. Tarasenkova, N., Burda, M., Bogatyreva, I., Bochko, O., Kolomiets, O. \& Serdiuk, Z. (2012) Independent and control works on geometry for class 11 (level of standard): [instructional manual]; ed. N. Tarasenkova, M. Burda. K.: Publishing House «Education». 48 p. Grif of the Ministry of Education and Science of Ukraine «Approved». (in Ukr.)

\section{TARASENKOVA Nina,}

Doctor of Science (Pedagogical Sciences), Professor, Head of the Department of Mathematics and Methods of Learning of Mathematics, Cherkasy Bohdan Khmelnytsky National University 


\section{SERDIUK Zoia,}

$\mathrm{PhD}$ (Pedagogical Sciences), Associate Professor of the Department of Mathematics and Methods of Learning of Mathematics, Cherkasy Bohdan Khmelnytsky National University

\section{ORGANIZATION OF THE STUDY OF VOLUMES OF SOLIDS IN THE SENIOR SPECIALIZED SCHOOL AT THE LEVEL OF STANDARD}

Abstract. Introduction. A state-of-art education is characterized by intensive attention to the schoolchildren and their universal development, their ability to find personal place in society and to be able to highest possible self-actualization in society. Therefore, one of main goals of school education is the development of those abilities of personality, which are needed both for a person and to society. The intensive formation of schoolchildren ability to think reasonably and consistently, analyze, compare, generalize, etc., namely the ability to make correct conclusions and build realistic predictions is considered as most important contribution of mathematical education to the general development of schoolchildren. All these skills students can form and develop during the study of geometry. However, the perception of the course of stereometry causes many difficulties for schoolchildren.

Purpose - to consider the peculiarities of the organization of study of the volumes of solids in the course of geometry at 11 grade on the level of standard.

Originality. In this paper, the some peculiarities of organization of the study of volumes of solids on the level of standard have been considered, namely: 1) volumes of polyhedrons; 2) volumes of cylinder and cone; 3) volume of sphere. During the study of these topics, it is necessary to familiar the schoolchildren with the notion of volume of geometrical figure, computing formulas of volume of prism, pyramid, parallelepiped, cube, cone, cylinder, sphere and respective rules. Also it is necessary to form the ability to calculate the volumes of mentioned bodies, use the volume as an additional element in problem solving procedure, interpret the graphically represented on figures solids and data, build the auxiliary planimetric drawings. In order to introduce on the lesson main notions from these topics on the level of standard it is appropriate to organize the practical work or demonstration experiment, when schoolchildren would consider the methods of volume measurements by pouring into another container, and also the rule of finding of volumes of solids should be defined with schoolchildren.

Conclusion. Therefore, the using of competence-based approach to organization of study of solids (polyhedrons, cylinder, cone, sphere) in the senior specialized school on the level of standard needs the development of system of special tasks and specific learning methodology of learning material presentation and mastering. Apt choosing of mathematical, interdisciplinary, practicallyoriented and applied tasks and didactically grounded organization of their solving is interpreted as guarantee of efficient schoolchildren learning of stereometry on the level of standard. At the result the well-grounded schoolchildren knowledge, skills and abilities, which are related to this topic are formed, also the important skills of person at whole are improved.

Keywords: study of stereometry, volumes of solids, level of standard.

Одержано редакиією 17.10.2018 p. Прийнято до публікаиї̈ 21.10.2018 p. 